\title{
VIOLÊNCIA CONTRA A PESSOA IDOSA: UMA QUESTÃO DE GÊNERO?
}

\section{VIOLENCE AGAINST ELDERLY PEOPLE: A QUESTION OF GENDER?}

\author{
Silvana de Pontes Carneiro ${ }^{1}$ \\ Édina Schimanski ${ }^{2}$
}

\begin{abstract}
RESUMO
Esta pesquisa teve como objetivo analisar a violência contra idosas no município de Guarapuava (PR), procurando conhecer os tipos de agressão mais frequentes e os perfis das vítimas e dos agressores. Com apoio em uma base documental, comprovou-se que prevalece a violência intrafamiliar contra vítimas femininas e, à luz da literatura e da legislação sobre o tema, são apresentadas conceituações, descrições e contextualizações das práticas violentas.
\end{abstract}

Palavras-chave: Mulheres idosas. Violência. Agressores.

\begin{abstract}
The objective of this research was to analyze the violence against elderly women in Guarapuava, Paraná, Brazil, trying to discover the more frequent types of aggression and the profiles of victims and aggressors. The analysis showed the prevalence of domestic violence against female victims. In addition, this paper demonstrated, through the literature and the legislation about the theme, some conceptualizations, descriptions and contextualization of the violent practices.
\end{abstract}

Keywords: Elderly women. Violence. Aggressors.

1 Assistente social. Professora do Curso de Serviço Social da Faculdade Guairacá. E-mail: socisilvana@hotmail.com

2 Assistente social. Mestre em sociologia pela Universidade Federal do Paraná. Doutora pela University of London - Institute of Education. Professora Adjunta do Departamento de Serviço Social e do Programa de Mestrado em Ciências Sociais Aplicada das Universidade Estadual de Ponta Grossa (PR). Email: edinaschi@gmail.com 


\section{Introdução}

Este trabalho resulta de estudos teóricos e de pesquisa documental acerca da violência contra idosos denunciada através do serviço Disque Idoso, que é mantido pelo Governo do Estado do Paraná, no âmbito de Guarapuava (PR), no período entre o início do ano de 2007 e julho de 2011. O referido serviço recebe denúncias de violência contra a pessoa idosa através do número telefônico 0800410001, que em seguida são repassadas aos respectivos municípios. Em Guarapuava a verificação das ocorrências é realizada in loco por profissionais da Secretaria Municipal de Assistência Social, para que sejam verificadas.

O contexto do objeto aqui enfocado tem natureza conceitual e legal, para o qual foram realizados estudos tomando-se como base estudos nas áreas da Sociologia, Política e História, bem como o Estatuto do Idoso, a Política Nacional do Idoso, a Lei Maria da Penha, entre outras.

Buscou-se catalogar, a partir dos registros realizados, as denúncias de violência quanto as suas formas de realização, gêneros e faixas etárias das vítimas, bem como em relação aos perfis dos agressores. Portanto, esse estudo se vale de fontes e de catalogação documentais, o que se configura como "[...] uma técnica importante na pesquisa qualitativa, seja complementando informações obtidas por outras técnicas, seja desvelando aspectos novos de um tema ou problema" (LÜDKE; ANDRÉ apud ABREU, 2012).

Quanto ao uso de documentos nesta pesquisa, convém observar que a

[...] riqueza de informações que deles podemos extrair e resgatar justificativa o seu uso em várias áreas das Ciências Humanas e Sociais porque possibilita ampliar o entendimento de objetos cuja compreensão necessita de contextualização histórica e sociocultural (SÁ-SILVA; ALMEIDA; GUINDANI, 2012).

O interesse na realização deste trabalho se liga à necessidade de conhecer o quadro de violência contra idosos que caracteriza as denúncias realizadas em Guarapuava (PR). Isto é indispensável para subsidiar políticas de prevenção e de atendimento na área, bem como proporcionar a identificação dos limites e das insuficiências das políticas e ações para atendimento a idosas vítimas de violência.

Ao combinar dados reais com as contribuições da literatura especializada, este trabalho de pesquisa se orienta compreendendo que é na prática social que se encontram, de maneira mais real e segura, as condições sobre as quais deve incidir a análise crítica. Também é na prática social que se encontram dialeticamente novas contradições que resultam em sínteses que, em forma social real, se traduzem em novas atitudes e novos arranjos culturais. Com esse fundamento, entende-se que

[...] as escolhas de cada indivíduo dependem não apenas de sua consciência e vontade individual vistas isoladamente, mas da cultura, da situação social, do acesso a serviços, da opinião da comunidade, amigos e familiares, aspectos que fazem parte da construção e reconstrução cotidiana destes indivíduos (SCHRAIBER, et al., 2005, p. 122).

A compreensão da configuração da violência e, para o caso deste trabalho, da violência contra idosos, a partir de seus determinantes materiais e históricos, requer a realização de um estudo por meio de uma abordagem qualitativa. Sem prender-se a quantificações, a pesquisa qualitativa "[...] corresponde a questões muito particulares na medida em que trabalha com o universo de significados, motivações, aspirações, crenças, valores e atitudes, o que corresponde a um espaço mais profundo da pesquisa" (MINAYO, 2007, p. 21).

\section{Violência: aspectos conceituais}

Nos últimos anos, observa-se um crescimento geral da violência que "[...] parece tão entranhada no nosso dia a dia que pensar e agir em razão dela deixa de ser um ato circunstancial para se transformar em ato natural e frequente" (OLIVEIRA, 2007 p. 28). Ela ainda tem um variado cenário histórico e cultural que perpassa todas as camadas sociais, sendo muitas vezes aceito como natural o mais forte dominar 
violentamente o mais fraco para exercer seu poder e obter vantagem na relação.

Poder e violência são fenômenos distintos, mas aparecem sempre juntos, sendo o poder o fator primário e predominante para desencadear a violência. Segundo Hannah Arendt, o "poder corresponde à habilidade humana não apenas para agir, mas para agir em concreto. O poder nunca é propriedade de um indivíduo; pertence a um grupo e permanece em existência apenas na medida em que o grupo conserva-se unido" (ARENDT, 1994, p. 36). Em paralelo, conforme aponta Faleiros, o poder aparece em todas as classes sociais como “[...] expressão real de uma relação de força que não só reprime os indivíduos, os instintos, uma classe ou grupo social, mas também a natureza" (FALEIROS, 2007, p. 28).

O poder do agressor pode ser usado para legitimar sua prática de violência, pois o poder "[...] estrutura os conflitos nas relações sociais pela maior ou menor força exercida de um grupo ou outra pessoa, seja pela submissão ou reação a esta força, seja pela pactuação de normas ou trocas" (FALEIROS, 2007, p. 29).

A violência também é definida como "[...] uma ação direta ou indireta, concentrada ou distribuída, destinada a prejudicar uma pessoa ou a destruí-la, seja em sua integridade física ou psíquica, seja em suas posses ou em suas participações simbólicas" (MICHAUD apud FALEIROS, 2004, p. 87). Complementando, Saffioti destaca que a violência causa a "[...] ruptura de qualquer forma de integridade da vítima: integridade física, psíquica, sexual, moral" (SAFFIOTI, 2007, p. 17).

Ainda sobre o conceito de violência, Michaud afirma que a

[...] violência se manifesta e se articula no impacto causado pelo prejuízo, na forma da ameaça que implica a imposição de si sobre o outro ou seu niquelamento, assim como a transgressão da norma, a eliminação da mediação da palavra e da mediação política e a provocação do medo e da insegurança. São dimensões relacionais do poder e da força contextualizados cultural, econômica e socialmente (MICHAUD apud FALEIROS, 2004, p. 87).
A respeito do caráter contextual da violência, Wievorka observa que "[...] a violência não tem, pois, um único significado e deve ser historicamente situada e compreendida [...] com significados históricos bem marcados" (WIEVORKA apud FALEIROS, s/d). Corroborando, Oliveira afirma que "[...] a história do mundo e do homem [mulher] é marcada pela violência. Em cada época e lugar essa violência toma contornos diferentes" (OLIVEIRA, 2007, p. 29). Portanto, todo ato de violência vem acompanhado de poder e submissão, reforçando contextos de aviltamento, pois

[...] vítimas de abusos físicos, psicológicos, morais e/ou sexuais são vistas por cientistas como indivíduos com mais probabilidades de maltratar, sodomizar outros, enfim, de reproduzir, contra outros, as violências sofridas, do mesmo modo como se mostrar mais vulneráveis às investidas sexuais ou violência física ou psíquica de outrem (SAFFIOTI, 2007, p. 18).

No âmbito das discussões acerca da violência, cabe considerar as práticas contra mulheres e contra idosos e, ainda mais especificamente, contra mulheres idosas. Isso se justifica, inicialmente, porque de acordo com dados de Oliveira, as mulheres são mais vulneráveis a todas as formas de violência, pois em "todo mundo, pelo menos uma em cada três mulheres já foi espancada, coagida ao sexo ou sofreu alguma outra forma de abuso durante a vida. $O$ agressor é geralmente um membro de sua própria família" (OLIVEIRA, 2007, p. 24). ${ }^{3}$ Em segundo lugar, urge discutir a questão da violência contra a mulher idosa pois são um atores sociais cujos direitos são abordados por duas leis, especificamente: o Estatuto do Idoso, no que diz respeito à faixa etária, e a Lei Maria da Penha, no que diz respeito ao gênero.

\footnotetext{
3 O fato de o agressor ser um membro da família muitas vezes dificulta que as vítimas os denunciem, por medo, por vergonha ou por dependência econômica. Contudo, segundo dados da Secretaria de Políticas para as Mulheres da Presidência da República, entre 2006 e 2010 o número de atendimentos anuais a mulheres vítimas de violência na Rede de Enfrentamento da Violência contra as Mulheres subiu de 46.423 para 552.034, somando 1.475 .912 atendimentos em todo o período (BRASIL, 2011). Essa Rede conta com um serviço telefônico para denúncias, o Disque 180.
} 


\section{Violência contra mulheres idosas - uma questão de gênero}

A violência contra a pessoa idosa "[...] acontece como uma quebra de expectativa positiva em relação àquelas que as cercam, sobretudo os filhos, cônjuges, parentes, cuidadores, a comunidade e a sociedade em geral" (MINAYO, 2008, p. 38). A autora ainda destaca que a Organização Mundial de Saúde (OMS) define as formas de violência contra a pessoa idosa como: "Ações ou omissões cometidas uma vez ou muita vezes, prejudicando a integridade física e emocional da pessoa idosa, impedindo o desempenho de seu papel social" (MINAYO, 2008, p. 38).

A violência contra a pessoa idosa "[...] é um fenômeno histórico universal, mas somente a partir da década de 70 passou a receber a atenção da sociedade internacional com a publicação de estudos sobre o assunto" (BERZINS, 2010, p. 279). No Brasil, os idosos começaram a sair da invisibilidade a partir da Lei número 8.842/94, que dispõe sobre a Política Nacional do Idoso, a qual tem como objetivo assegurar os direitos sociais do idoso, criando condições para promover sua autonomia, integração e participação efetiva na sociedade. ${ }^{4}$

Como a violência contra a pessoa idosa é um dado mundial, a Organização das Nações Unidas (ONU) realizou a II Assembleia Mundial do Envelhecimento, de 08 a 12 de abril de 2002, na qual foi aprovado o Plano Internacional sobre o Envelhecimento. O evento afirmou como prioritária a aplicação da declaração dos Direitos Humanos (BRASIL, 2005).

Segundo o Plano de Ação para o Enfrentamento da Violência Contra a Pessoa Idosa,

No Brasil, segundo dados do Instituto Brasileiro de Geografia e Estatística (IBGE), do ano de 2003, há, hoje, aproximadamente, 16,4 milhões de idosos, definidos como população de 60 anos e mais de idade. Esse número de idosos já corresponde a mais de $6 \%$ da população brasileira. Esse dado é altamente relevante porquanto a mudança na distribuição etária de um país altera o perfil das

\footnotetext{
4 A mesma Lei número 8.842/94 cria o Conselho Nacional do Idoso a quem compete a formulação, coordenação, supervisão e avaliação da Política nacional do Idoso.
}

políticas sociais, exigindo estratégias e implementação de benefícios, serviços, programas e projetos relacionados à promoção dos direitos humanos dos idosos, notadamente quando se tem em vista que significativa parcela desse segmento encontra-se em situação de abandono ou sendo vítima de maus-tratos praticados na maioria das vezes pelos seus próprios familiares. As vítimas preferenciais são as mulheres idosas em razão da histórica marginalização a qual este gênero está submetido (BRASIL, 2005).

Como se verá adiante, a maioria das denúncias feitas através do serviço Disque Idoso no âmbito de Guarapuava é de violência contra mulheres idosas. Sabe-se que o tema da violência contra mulheres só recentemente ganhou a devida importância, através da militância pela aprovação e aplicação da Lei Maria da Penha. O tema da violência contra idosos é de tratamento ainda mais recente e, especificamente no caso da violência contra a mulher idosa, ainda requer maiores estudos. Neste sentido, a violência contra a idosa passa pela questão das relações de gênero presentes na sociedade. ${ }^{5}$ Segundo Daphne “[...] a violência contra mulheres idosas só muito recentemente entrou na agenda política e ainda não existe muita informação detalhada sobre a prevalência da violência exercida contra as mulheres idosas" (DAPHNE, 2009). A respeito da política de atendimento ao idoso, Teixeira afirma tratar-se de "[...] uma legislação moderna que reforça a característica brasileira de legislações complexas, ricas, de proteção social, entretanto, com nítido caráter formal, legalista, que não se expressa em ações efetivas de proteção" (TEIXEIRA, 2006, p. 266). A autora ainda ressalta que

[...] a setorialização da política e a delimitação dos grupos de destino de proteção social por critérios etários, gênero, raça, renda, dentre outros, são,

\footnotetext{
5 Para as ciências sociais e humanas, o conceito de gênero se refere à construção social do sexo anatômico. [...] gênero significa que homens e mulheres são produtos da realidade social e não decorrência da anatomia de seus corpos. [...] O modo como homens e mulheres se comportam em sociedade corresponde a um intenso aprendizado sociocultural que nos ensina a agir conforme as prescrições de cada gênero." (Gênero e Diversidade na escola: Formação de Professoras/ES em Gênero, Orientação Sexual e Relações Étnico-Raciais. Livro de Conteúdo. Módulo II. Versão2009- Rio de Janeiro: CEPESC; Brasília: SPM, 2009.
} 
ao mesmo tempo ampliação dos grupos cobertos, como também de critérios que mascaram a origem de classe, e as desigualdades na construção dos problemas sociais (TEXEIRA, 2008, p. 266).

As políticas de atendimento a mulheres idosas ainda são fragmentadas e por isso deixam lacunas, pois " [...] nascem e são executadas em resposta às necessidades postas pelo desenvolvimento capitalista, expressando uma profunda contradição na regulação social na modernidade" (ROCHA apud SERRA e DIAS, 2011).

Na maioria das vezes, a violência é cometida em casa pelos próprios familiares. De acordo com Daphne, a "[...] violência, os maus-tratos e os abusos contra mulheres idosas nas famílias incluem todos os tipos de violência ou comportamento abusivo, por parte dos membros da família ou de seus cuidadores" (DAPHNE, 2009). Acrescenta-se a isso que

Quando vítimas de maus-tratos praticados pelos familiares, os idosos, e mais especialmente as idosas, em virtude de sua fragilidade física e emocional, temem denunciar os seus agressores por medo de sofrer represálias e também em virtude de, muitas vezes, alimentarem sentimento de afeto em relação aos seus algozes (BRASIL 2005).

A Lei número 10.741/2003 (Estatuto do Idoso) assegura em seu Art. $4^{\circ}$ que "[...] nenhum idoso será objeto de qualquer tipo de negligência, discriminação, violência, crueldade ou opressão, e todo atentado aos seus direitos, por ação ou omissão, será punido na forma da lei" (BRASIL, 2006). A mesma lei, em seu Art. $3^{\circ}$, afirma que é "dever de todos zelar pela dignidade do idoso, colocando-o a salvo de qualquer tratamento desumano, violento, aterrorizante, vexatório ou constrangedor".

As mulheres idosas, além do Estatuto do Idoso, contam com a Lei Maria da Penha, a qual assegura no seu Art. $2^{\circ}$ que

[...] toda mulher, independentemente de classe, raça, etnia, orientação sexual, renda, cultura, nível educacional, idade e religião, goza dos direitos fundamentais inerentes à pessoa humana, sendo-lhe asseguradas as oportunidades e facilidades para viver sem violência, preservar sua saúde física e mental e seu aperfeiçoamento moral, intelectual e social (BRASIL, 2006).

Apesar dos esforços empreendidos pelas agências nacionais, e até mesmo internacionais (ver, por exemplo, ONU), a erradicação da violência contra a mulher e, nesse caso, contra a mulher idosa ainda está longe de ser atingida. A ONU estima que 70\% das mulheres no mundo sofrem violência durante alguma etapa de sua vida (na infância, na vida adulta ou na velhice). ${ }^{6}$

Cumpre agora, para o desenvolvimento desse estudo, elencar e descrever as seguintes formas de violência: física, psicológica, moral, patrimonial, por negligência e maus-tratos. Esse conjunto abrange as formas registradas pelo serviço Disque Idoso no âmbito do município de Guarapuava (PR), e as respectivas descrições serão embasadas na legislação já citada e em contribuições de teóricos sobre o tema, de modo a expor, principalmente, as questões referentes ao gênero feminino situado na chamada terceira idade.

\section{Tipos de violência}

A violência física ${ }^{7}$ contra a mulher não é uma novidade. Na Idade Média, por exemplo, segundo Oliveira, "[...] os maus tratos infligidos às mulheres eram tolerados e até enaltecidos, a fim de corrigi-las. No Brasil na época colonial, os maridos tinham a permissão para 'emendarem' suas companheiras pelo uso da chibata" (OLIVEIRA, 2007, p. 101).

O tipo físico de violência tem efeitos imediatos sobre as vítimas, os quais variam de traumatismos até a morte:

\footnotetext{
6 Segundo dados disponíveis em: http://www.onu.org.br/unase/, acessados em 25/01/2012.

7 Segundo dados da Secretaria de Políticas para as Mulheres, da Presidência da República, as denúncias de violência contra a mulher feitas através do serviço Ligue 180 durante o primeiro semestre de 2010, somaram 62.301 registros, sendo que destes, 36.059 foram de violência física. Especificamente no estado do Paraná, de 2.558 denúncias de violência contra mulheres, 1.463 foram de violência física (BRASIL, 2011).
} 
As consequências da violência sobre a saúde das mulheres, no caso de abuso pelo parceiro, com agressões de todos os tipos, podem ser classificadas fatais e não-fatais. Nas fatais encontram-se homicídios, suicídios e mortalidade materna relacionada à AIDS. Já nas não-fatais se agrupam em consequências de saúde física, lesões, deficiência funcional, sintomas físicos, invalidez, obesidade grave, depressão (OLIVEIRA, 2007, p. 40).

A violência física pode deixar sequelas visíveis permanentes nas mulheres. São relacionadas "[...] à redução da produção em todos os sentidos, diminuição da auto-estima, da força de trabalho, da criatividade, do prazer pela vida e da coragem de enfrentá-la" (OLIVEIRA, 2007, p.100); ao “[...] consumo de tranqüilizantes, álcool e fumo" (OLIVEIRA, 2007, p.86); e a outras formas de sofrimento em que as vítimas seguem "[...] enfrentando a violência a seu modo" (OLIVEIRA, 2007, p 38).

Oliveira ainda lembra que "[...] no Brasil, de cada cinco mulheres, três já sofreram algum tipo de violência. É um drama vivido indistintamente tanto pelas classes mais altas como pelas mais baixas" (2007, p. 87).

A violência física contra a mulher já é considerada um caso de saúde pública no Brasil, pois “[...] as mulheres que sofrem de violência física e sexual têm maior chance de utilizar mais frequentemente os serviços de saúde" (OLIVEIRA, 2007, p. 38) e, quando os sinais de violência não são identificados pelos profissionais da área da saúde é possível que as vítimas desenvolvam outras doenças "[...] conhecidas como poliqueixas, ou aquelas que sentem vários sintomas, dores e incômodos, difíceis de serem localizadas e que não conseguem nem explicar seus sofrimentos" (TELES; MELO, 2009, p. 52).

A violência psicológica contra a mulher ${ }^{8}$ é definida pela Lei Maria da Penha em seu Artigo $7^{\circ}$, como

[...] qualquer conduta que lhe cause dano emocional e diminuição da auto-estima ou que lhe prejudique

\footnotetext{
8 De acordo com a Secretaria de Políticas para as Mulheres, da Presidência da República, das 62.301 denúncias de violência contra a mulher feitas através do serviço Ligue 180 no primeiro semestre de 2010, 16.071 foram de violência psicológica. No Paraná, de 2.558 denúncias, 672 foram de violência psicológica (BRASIL, 2011).
}

e perturbe o pleno desenvolvimento ou que vise degradar ou controlar suas ações, comportamentos, crenças e decisões, mediante ameaça, constrangimento, humilhação, manipulação, isolamento, vigilância constante, perseguição contumaz, insulto, chantagem, ridicularização, exploração e limitação do direito de ir e vir ou qualquer outro meio que the cause prejuízo à saúde psicológica e à autodeterminação (BRASIL, 2006).

Faleiros afirma que ocorre violência psicológica sempre que se verifica

[...] uma relação de poder com uso da força da autoridade ou da ascendência sobre o outro, de forma inadequada e com excesso ou descaso; inversão de papéis de proteção e ruptura de confiança; humilhação; chantagem; desvalorização; esconder informações necessárias e significantes; provocar raiva ou choro; deixar longo tempo sozinho; amedrontar; separar de pessoas queridas; desqualificação; negação de direitos e desrespeito (FALEIROS, 2007, p. 46)

Segundo Oliveira, a violência psicológica pode causar doenças psíquicas cujos principais sintomas são os seguintes: "[...] o entusiasmo cai, surge um sentimento de impotência para influenciar os fatos ou os próprios sentimentos a respeito deles. Desenvolvem-se sentimentos de impotência e de inutilidade" (2007, p. 42). Tal situação "[...] não afeta somente a vítima de forma direta. Ela atinge a todos que presenciam ou convivem com a situação da violência" (SILVA et al., 2007, p. 98), o que tende a gerar prejuízos contínuos porque "[...] perceber que está vivendo uma situação de violência pode ser difícil para algumas mulheres. Muitas acabam se enganando e fingindo que aquela violência toda não está acontecendo" (SILVA et al., 2007, p.100).

A violência moral é definida pela Lei Maria da Penha, em seu Artigo $7^{\circ}$, inciso V, como “[...] qualquer conduta que configure calúnia, difamação ou injúria" contra mulheres, independentemente de sua idade (BRASIL, 2006). O Estatuto do Idoso, por sua vez, deixa claro em seu Artigo $2^{\circ}$ que não se pode impedir "[...] todas as oportunidades e facilidades, para preservação de sua saúde física e mental e seu aperfeiçoamento moral, intelectual, espiritual 
e social, em condições de liberdade e dignidade" (BRASIL, 2005).

A violência patrimonial é muito frequente entre os idosos devido a sua fragilidade física e mental. Faleiros afirma que ocorre violência patrimonial em toda

[...] relação de poder que implica a pressão sobre o outro ceder dinheiro, cobrado com base em chantagens e abusos de confiança; retenção de cartão, salário, loterias, aluguel; pressão pra vender a casa ou bens; falsificação de assinaturas; pressão pra fazer testamentos ou doações; apropriação de compras; impedimentos de informações sobre o dinheiro e as contas (2007, p. 47).

A violência patrimonial é descrita pela Lei Maria da Penha no Artigo $7^{\circ}$, inciso IV, como "[...] retenção, subtração de seu dinheiro, destruição parcial ou total de seus bens objetos, instrumentos de trabalho, documentos pessoais, bens e recursos econômicos" (BRASIL, 2006).

A negligência, forma de violência muito comum contra os idosos, se caracteriza como

[...] abandono - descuido, desamparo; desresponsabilização e descompromisso do cuidado e de afeto; medicação descuidada; vestimenta descuidada; assistência de saúde incompleta ou descuidada; deixar de lado nos contatos sociais; descuidado na comida (FALEIROS, 2007, p. 46).

Esta forma de violência "[...] diz respeito à recusa ou omissão de cuidados devidos e necessários aos idosos, por parte dos responsáveis familiares, é uma das formas de violência contra os idosos mais presente no país" (FIGUEIREDO et al., 2010, p. 112).

É importante observar que maus tratos se constituem como uma forma de violência por resultarem em aviltamento, embora sua descrição possa combinar vários aspectos dos demais tipos de violência. No contexto aqui estudado, são considerados como maus tratos a privação da liberdade e da privacidade, o isolamento, vocabulários e tons agressivos nos tratamentos e outros afins. Assim, os maus tratos não se reduzem à violência física, psicológica, moral, patrimonial ou por negligência, embora possam conter elementos de todas elas.

\section{Estatística da violência contra idosos em Guarapuava (PR)}

No período de janeiro de 2007 a julho de 2011 foram registradas 138 denúncias de violência contra a pessoa idosa através do Disque Idoso em Guarapuava (PR). Segundo os dados, no primeiro ano de registros, 2007, o número de denúncias foi apenas 6 , enquanto nos anos seguintes a média foi de 33 denúncias anuais, representando significativo aumento do uso do serviço Disque Idoso.

Quadro 1: Evolução dos números anuais de denúncias no período

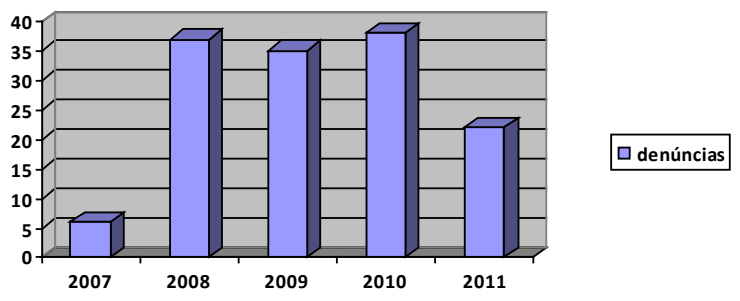

Observa-se que a média semestral de denúncias entre 2007 e 2010 foi de 15,2, enquanto no primeiro semestre de 2011 foram recebidas 22 denúncias, o que indica uma tendência de maior uso do serviço Disque Idoso pela população de Guarapuava.

Quadro 2: Evolução de quantidades de percentuais de denúncias no período

\begin{tabular}{|c|c|c|}
\hline Anos & Quantidades & Percentuais \\
\hline 2007 & 6 & $4,3 \%$ \\
\hline 2008 & 37 & $26,8 \%$ \\
\hline 2009 & 35 & $25,4 \%$ \\
\hline 2010 & 38 & $27,6 \%$ \\
\hline 2011 & 22 & $15,9 \%$ \\
\hline Totais & 138 & $100 \%$ \\
\hline
\end{tabular}

No que diz respeito aos gêneros das vítimas, os relatórios indicam que no período foram feitas 54 denúncias de violência contra idosos e 84 contra 
idosas, sendo, portanto, 39\% das vítimas do sexo masculino e $61 \%$ do sexo feminino.

Quadro 3: Evolução do número e de percentuais de denúncias quanto aos gêneros das vítimas

\begin{tabular}{|c|c|c|c|}
\hline \multirow{2}{*}{ Anos } & Gêneros & Quantidades & $\begin{array}{c}\text { Percentuais } \\
\text { anuais }\end{array}$ \\
\hline \multirow{2}{*}{2007} & Masculino & 4 & $66,6 \%$ \\
\cline { 2 - 4 } & Feminino & 2 & $33,3 \%$ \\
\hline \multirow{2}{*}{2008} & Masculino & 12 & $32,4 \%$ \\
\cline { 2 - 4 } & Feminino & 25 & $67,6 \%$ \\
\hline \multirow{2}{*}{2009} & Masculino & 17 & $48,5 \%$ \\
\cline { 2 - 4 } & Feminino & 18 & $51,5 \%$ \\
\hline \multirow{2}{*}{2010} & Masculino & 13 & $34,2 \%$ \\
\cline { 2 - 4 } & Feminino & 25 & $65,8 \%$ \\
\hline \multirow{2}{*}{2011} & Masculino & 8 & $36,3 \%$ \\
\cline { 2 - 4 } & Feminino & 14 & $63,7 \%$ \\
\hline \multirow{2}{*}{ Totais } & Masculino & 54 & $39 \%$ \\
\cline { 2 - 4 } & Feminino & 84 & $61 \%$ \\
\cline { 2 - 4 } & Geral & $\mathbf{1 3 8}$ & $\mathbf{1 0 0 \%}$ \\
\hline
\end{tabular}

No triênio de 2008 a 2010 repete-se anualmente a predominância de denúncias de violência contra mulheres idosas em relação à violência contra homens idosos, o que se verifica também como tendência para 2011, quando, no primeiro semestre, $63,7 \%$ das denúncias apontaram vítimas do sexo feminino.

Quadro 4: Evolução de denúncias anuais quanto aos gêneros das vítimas

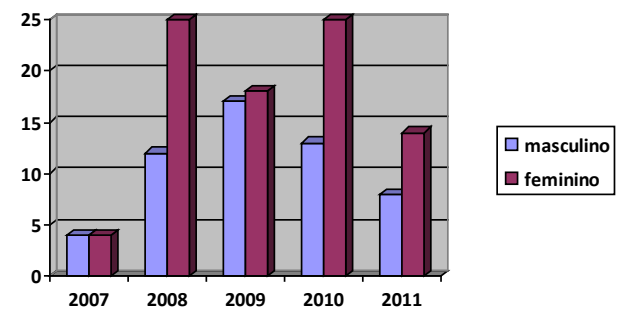

As denúncias foram tabuladas também quanto às seguintes faixas etárias das vítimas: de 60 a 70 anos, de 71 a 80 anos, de 81 a 90 anos e acima de noventa anos.

Quadro 5: Quantidades e percentuais das vítimas quanto aos gêneros e às faixas etárias

\begin{tabular}{|c|c|c|c|c|}
\hline \multirow{2}{*}{ Homens } & $\begin{array}{c}\text { 60 a 70 } \\
\text { anos }\end{array}$ & $\begin{array}{c}\mathbf{7 1} \text { a 80 } \\
\text { anos }\end{array}$ & $\begin{array}{c}\mathbf{8 1} \text { a 90 } \\
\text { anos }\end{array}$ & $\begin{array}{c}\text { Acima de 90 } \\
\text { anos }\end{array}$ \\
\cline { 2 - 5 } & 29 & 14 & 8 & 3 \\
\hline \multirow{2}{*}{ Mulheres } & $37,5 \%$ & $30,4 \%$ & $30,7 \%$ & $60 \%$ \\
\cline { 2 - 5 } & $52,5 \%$ & 32 & 18 & 2 \\
\hline Totais & $\mathbf{6 1}$ & $\mathbf{4 6}$ & $\mathbf{2 6}$ & $\mathbf{5}$ \\
\hline
\end{tabular}

Percebe-se que a maior parte das vítimas se situa na faixa etária entre 60 e 70 anos, embora quanto aos gêneros as mulheres tenham igual incidência na faixa etária entre 60 e 80 anos.

Quadro 6: Distribuição das vítimas quanto aos gêneros e às faixas etárias

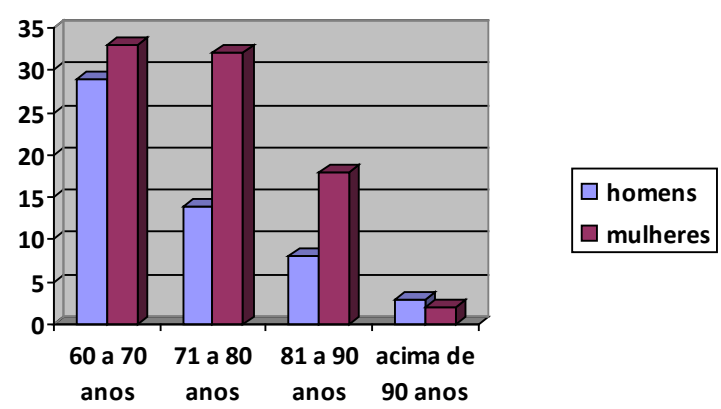

Todos os agressores denunciados ${ }^{9}$ tinham relações familiares com as vítimas, sendo que os filhos foram apontados com maior frequência.

Percebe-se que, dos agressores identificados, os que apresentam maior frequência entre as denúncias

Quadro 7: Quantidades e percentuais de ocorrências por perfis de agressores

\begin{tabular}{|c|c|c|c|c|c|c|c|c|c|c|}
\hline Filho(a) & Neto(a) & Esposo & Esposa & Nora & Sobrinho(a) & Outro & Irmã & Cunhado & Primo & Genro \\
\hline 78 & 8 & 8 & 5 & 8 & 5 & 9 & 3 & 1 & 1 & 1 \\
\hline $61,5 \%$ & $6,3 \%$ & $6,3 \%$ & $3,9 \%$ & $6,3 \%$ & $3,9 \%$ & $7,1 \%$ & $2,3 \%$ & $0,7 \%$ & $0,7 \%$ & $0,7 \%$ \\
\hline
\end{tabular}

9 O número de ocorrências de violência é de 127. Essa quantidade é inferior ao número de denúncias recebidas (138) pelo serviço Disque Idoso durante o período dessa pesquisa porque, após verificação in loco, 11 casos não procediam, o que representa um percentual de $7,9 \%$ de casos de violência denunciados e não confirmados. 
Quadro 8: Distribuição de ocorrências quanto aos perfis dos agressores

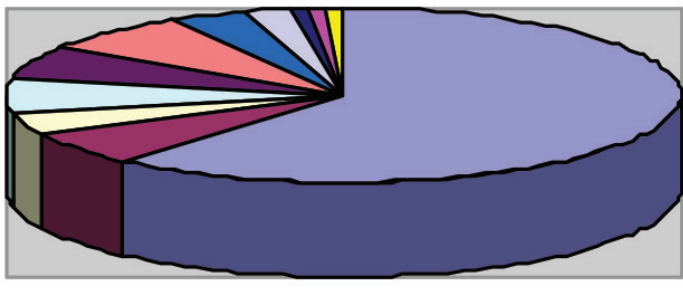

$\square$ Filhos $\square$ Esposos $\square$ Esposas $\square$ Netos $\square$ Noras $\square$ Outros

$\square$ Sobrinhos $\square$ Irmãs Cunhado $\square$ Primo $\square$ Genro

Quadro 9: Quantidades e percentuais das vítimas quanto ao estado civil

\begin{tabular}{|c|c|c|c|c|}
\hline Viúvos & Casados & Não informaram & Solteiros (sozinhos) & Separados \\
\hline 42 & 37 & 26 & 25 & 8 \\
\hline $30,5 \%$ & $26,8 \%$ & $18,8 \%$ & $18,1 \%$ & $5,8 \%$ \\
\hline
\end{tabular}

Quadro 10: Distribuição das vítimas quanto ao estado civil

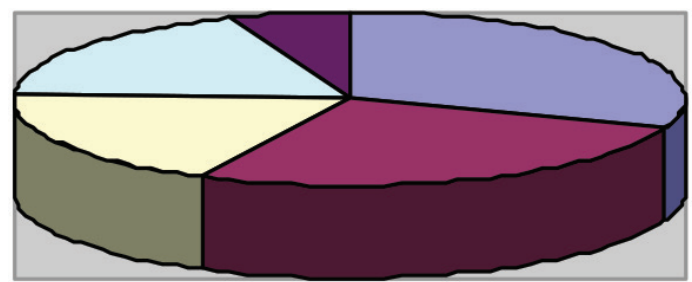

$\square$ Viúvos $\quad \square$ Casados $\quad \square$ Não informaram $\quad \square$ Solteiros (sozinhos) $\quad$ Separados

Quadro 11: Quantidades e percentuais de ocorrências por tipos de violência ${ }^{10}$

\begin{tabular}{|c|c|c|c|c|c|}
\hline Maus tratos & Negligência & Psicológica & Patrimonial & Moral & Física \\
\hline 114 & 91 & 74 & 62 & 51 & 44 \\
\hline $26,5 \%$ & $20,9 \%$ & $16,9 \%$ & $14,3 \%$ & $11,6 \%$ & $9,7 \%$ \\
\hline
\end{tabular}

Quadro 12: Distribuição de ocorrências por tipos de violência

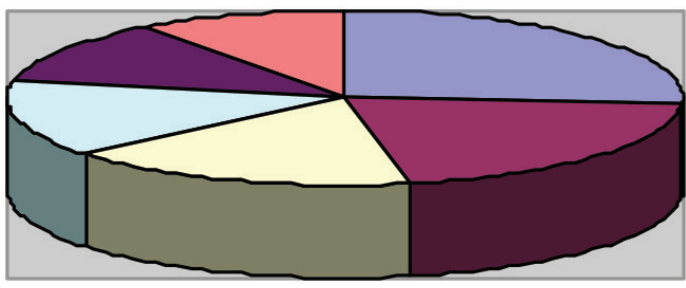

\begin{tabular}{llllll}
\hline Maus tratos $\quad \square$ Negligência & $\square$ Psicológica
\end{tabular} Patrimonial $\quad \square$ Moral $\quad \square$ Física


são os que convivem cotidianamente com as vítimas, no caso filhos, cônjuges e netos.

A pesquisa também abrangeu o estado civil dos idosos, verificando-se que predominam os viúvos. A seguir, o quadro de quantificação dos idosos quanto a esse quesito.

No quadro abaixo nota-se a relação direta entre os estados civis dos idosos e os perfis dos agressores. Viúvos e casados correspondem juntos a 79 vítimas de violência, enquanto os filhos agressores são 78 .

Os tipos de violência denunciados através do Disque Idoso no período delimitado para essa pesquisa abrangem as formas física, moral, patrimonial, psicológica, por negligência e por maus tratos.

Os tipos de violência denunciados pelo serviço Disque Idoso foram assim quantificados:

Considerando-se o número de denúncias que foram recebidas (138) e o número de ocorrência de violência em seus diversos tipos (436), obtém-se uma média de três formas diferentes de violência sofridas por idosos.

A preponderância de maus tratos evidencia que as vítimas são agredidas de maneiras variadas, posto que há combinação entre as diferentes formas de violência em cada denúncia e também porque o próprio conceito de maus tratos remete a uma mescla de aviltamentos.

\section{Conclusão}

Os estudos realizados nesta pesquisa apresentam a violência contra a pessoa idosa denunciadas através do Disque Idoso em Guarapuava (PR), tendo como objeto a violência contra a mulher idosa teorizada em seus aspectos históricos, sociológicos, políticos e sociais. Esses aspectos denunciam que as ações violentas não podem ser consideradas como naturais, mas sim como um danoso produto cultural na sociedade.

Outra característica da violência que ficou demonstrada pelos estudos teóricos é a sua universalidade, ou seja, que se trata de um fenômeno que não se restringe a âmbitos geográficos, econômicos ou sociais específicos.

\footnotetext{
10 Observa-se que o número de ocorrências de violência (436) é superior ao número de denúncias (138) recebidas pelo Disque Idoso porque muitas vezes vários tipos de violência foram denunciados em um único caso.
}

O aumento das denúncias de violência contra a pessoa idosa deve-se à maior divulgação do Estatuto do Idoso. O aumento anual do número de denúncias de violência contra mulheres idosas pode estar vinculado a uma combinação de maior divulgação do Estatuto do Idoso e da Lei Maria da Penha.

Diante dessa amplitude de número de violência as mulheres idosas ainda são as que mais sofrem com a violência. Identificou-se na pesquisa que as violências praticadas contra idosos são: maus tratos, negligência, psicológica, patrimonial, moral e física. Os agressores são predominantemente membros da família: netos, sobrinhos, esposos, noras, genros, primos, irmãs, e outros que não são membros da família, entre os quais os filhos aparecem na maioria das vezes como algozes de seus próprios pais.

Na região de Guarapuava houve um resultado positivo no que diz respeito às políticas de divulgação dos direitos da pessoa idosa e do serviço de denúncia Disque Idoso; contudo os resultados desta pesquisa comprovaram a necessidade de se promover algum trabalho de orientação junto aos familiares dos idosos em relação aos direitos desses últimos e aos deveres de cuidados para com eles previstos em lei.

O presente trabalho contribuiu para evidenciar que, entre os idosos, as mulheres são as que mais sofrem violência. As formas de violências praticadas contra elas são as mesmas praticadas contra os idosos, sendo que os agressores são membros da família, o que dificulta o trabalho dos profissionais, já que os idosos não denunciam as agressões, e, quando feitas, são realizadas por vizinhos ou anonimamente.

Portanto, para atender os idosos vítimas de violência, é preciso investir em ações mais concretas, já que no município não existe um trabalho contínuo de prevenção da violência contra os idosos. Esse trabalho deve se articular em rede com uma equipe interdisciplinar, já que os idosos vítimas de violência permanecem juntos a seus agressores.

\section{REFERÊNCIAS}

ABREU, Sandra Elaine Aires de. Pesquisa e análise documental. Disponível em: $<$ http://www.unievangelica. edu.br/gc/imagens/noticias/1817/file/01>. Acesso em: 05 janeiro 2012 . 
ARENDT, Hannah. Sobre a violência. Trad. André Duarte. Rio de Janeiro: Relume Dumará, 1994.

BERZINS, Marília Anselmo Viana da Silva. Violência contra a pessoa idosa: o que fazer? In: BRASIL. Secretaria Especial dos Direitos Humanos, Subsecretaria de Promoção e Defesa dos Direitos Humanos. Manual cuidar melhor e evitar a violência: manual do cuidador da pessoa idosa. Brasília: 2008. p. 46-50.

BOUDON, Raymond; BOURRICAUD, François. Dicionário crítico de sociologia. 2.ed. São Paulo: Editora Ática, 2004.

BRASIL. Ministério da Casa Civil. Lei n. 11.340, de 7 de agosto de 2006. Lei Maria da Penha.

BRASIL. Presidência da República. Casa Civil. Lei número 10.741/2003. Estatuto do Idoso.

BRASIL. Presidência da República. Subsecretaria de Direitos Humanos. Plano de ação para o enfrentamento da violência contra a pessoa idosa. Brasília: Subsecretaria de Direitos Humanos, 2005.

BRASIL. Secretaria de Políticas para as Mulheres da Presidência da República. Perfil da violência doméstica a partir do balanço semestral da Central de Atendimento à Mulher. Disponível em: <http://www.sepm.gov.br/noticias/ ultimas noticias $/ 2010 / 08 /$ teste $/$ ? searchterm $=36.059$ > Acesso em: 20 janeiro 2012.

DAPHNE. Violência contra mulheres idosas em contexto familiar: reconhecer e agir. União Européia, 2009. Disponível em: <http://www.roteskreuz.at/fileadmin/user_upload/PDF/ GSD/Brochure-Portugal.pdf $>$. Acesso em: 31 julho 2011.

FALEIROS, Vicente de Paula. A questão da violência. In: SOUZA JR., José Geraldo de. Educando para os direitos humanos: pautas pedagógicas para a cidadania na Universidade. Brasília: Síntese, 2004.

Violência contra pessoa idosa: ocorrências, vítimas e agressores. Brasília/DF: Editora Universa, 2007.

FIGUEIREDO, Ana Elisa Bastos, et al. Centro de Atenção e Prevenção à Violência Contra a Pessoa Idosa e Observatório Nacional do Idoso: uma questão de direitos. In: BERZINS, Marília Viana; MALAGUTTI, Wilian. Rompendo o silêncio: faces da violência na velhice. São Paulo: Martinari, 2010. p. 109-121.

GÊNERO e diversidade na escola: formação de professoras/ ES em gênero, orientação sexual e relações étnico-raciais. livro de conteúdo. Módulo II. Versão 2009. Rio de Janeiro: CEPESC; Brasília: SPM, 2009.

MENDONÇA, Jurilza Maria Barros de. Direitos humanos e Pessoa Idosa. In: BERZINS, Marília Viana; MALAGUTTI, Wilian. Rompendo o silêncio: faces da violência na velhice. São Paulo: Martinari, 2010. p.60-70.
MINAYO, Maria Cecília de Souza. Pesquisa social. 25. ed. Petrópolis: Vozes, 2007.

Violência e maus-tratos contra a pessoa idosa: é possível prevenir e superar. In: BRASIL. Secretaria Especial dos Direitos Humanos, Subsecretaria de Promoção e Defesa dos Direitos Humanos. Manual cuidar melhor e evitar a violência: manual do cuidador da pessoa idosa. Brasília: 2008. p.38-45.

CUIDAR melhor e evitar a violência. manual do cuidador da pessoa idosa. Disponível em: <http://www.ciape.org.br/ manual_cuidador.pdf $>$. Acesso em: 09 agosto 2011.

OLIVEIRA, Eliany Nazaré. Pancada de amor dói e adoece: violência física contra mulheres. Sobral: Editora Uva, 2007.

REVISTA da educação, n.161, 15 de novembro de 2006. Disponível em: $<\mathrm{http} / /$ www.apagina.pt/?aba $=7 \&$ cat $=161 \&$ $\mathrm{doc}=11929 \& \mathrm{mid}=2>$. Acesso em: 03 novembro 2011.

SÁ-SILVA, Jakcson Ronie; ALMEIDA, Cristóvão Domingos de; GUINDANI, Joel Felipe. Pesquisa documental: pistas teóricas e metodológicas. Revista Brasileira de História e Ciências Sociais. Disponível em: <http://www.rbhcs. com/index_arquivos/Artigo.Pesquisa\%20documental.pdf $>$. Acesso em: 05 janeiro 2012.

SAFFIOTI, Heleieth I. B. Gênero, patriarcado, violência. São Paulo: Fundação Perseu Abramo, 2007.

SCHRAIBER, Lilia Blima; D’OLIVEIRA, Ana Flávia Pires Lucas; FALCÂO, Márcia Thereza Couto; FIGUEIREDO, Wagner dos Santos. Violência dói e não é direito: a violência contra a mulher, a saúde e os direitos humanos. São Paulo: UNESP, 2005

SERRA, Jacira do Nascimento; DIAS, Marly de Jesus Sá. Políticas públicas para mulheres na velhice: reflexões sobre os interesse na pauta do PAISM. Disponível em: $<$ http://www.joinpp.ufma.br/jornadas/joinppII/pagina PGPP/Trabalhos2/Jacira\%20do\%2>. Acesso em: 01 agosto 2011.

SILVA, Luciane Lemos da; COELHO, Elza Berger Salema; CAPONI, Sandra Noemi Cucurullo de. Violência silenciosa: violência psicológica como condição da violência física doméstica. Interface (Botucatu), v.11, n.21, p. 93-103, 2007. Doi: http://dx.doi.org/10.1590/S1414-32832007000100009

TEIXEIRA, Solange Maria. Envelhecimento e trabalho no tempo do capital: problemática social e as tendências das formas de proteção social na sociedade brasileira contemporânea. Tese (Doutorado). São Luiz: Universidade Federal do Maranhão, 2006.

Recebido em dezembro de 2013. Aceito em fevereiro de 2014. 